ESCRITAS Vol. 9 n. 2 (2017) ISSN 2238-7188 p. 131-144

\title{
ENSINO E APRENDIZAGEM EM HISTÓRIA: UMA REFLEXÃO A PARTIR DA PESPECTIVA DE JORN RÜSEN.
}

\section{TEACHING AND LEARNING IN HISTORY: A REFLEXION FROM JORN RÜSEN'S PERSPECTIVE.}

\author{
Marcelo Marcos de Araújo ${ }^{1}$ \\ Braz Batista Vas ${ }^{2}$
}

\begin{abstract}
RESUMO: Este artigo aborda o ensino e aprendizagem em História na perspectiva da didática da História do filósofo alemão Jörn Rüsen. Este autor contribuiu ao alçar a didática da História e sua importância na aprendizagem dos alunos como tema de destaque no debate epistemológico da História, ao identificar como a aprendizagem da História pode ser ensinada e de como os alunos podem aprender e compreender a História a partir da relação do passado, presente e do lugar em que o mesmo ocupa socialmente, atribuindo significados aos conteúdos históricos apresentados pelos professores de história. Rüsen destaca a importância da didática da história como o principal elemento da concretização do aprendizado histórico, a partir de significados que o aluno possa ter sobre aspectos de sua vida social e cultural.
\end{abstract}

PALAVRAS CHAVES: Didática da História; Aprendizado Histórico; Consciência Histórica.

\begin{abstract}
This article deals with teaching and learning in History in the perspective of the historical didactics of the German philosopher Jörn Rüsen. This author contributed to raise the didactics of History and its importance in the learning of students as a prominent theme in the epistemological debate of History. He identifies how the learning of History can be taught and how students can learn and understand History from the relation of the past, present and place in which it occupies socially by attributing meanings to the historical contents presented by history teachers. Rüsen emphasizes the importance of historical didactics as the main element of the achievement of historical learning based on meanings that the student can have about aspects of his/her social and cultural life.
\end{abstract}

KEYWORDS: Didactics of History; Historical Learning; Historical Consciousness.

\footnotetext{
${ }^{1}$ Mestre em Ensino de História pela UFT. Professor da rede Estadual de Ensino nos estados Piauí e Maranhão. E-mail: marcelosmarcus@hotmail.com.

2 Doutor em História pela UNESP - Franca. Professor Adjunto do Curso de História da UFT - Câmpus de Araguaína. E-mail: brazbv@gmail.com.
} 


\section{Introdução}

O ensino de História como qualquer outra disciplina científica, possui seus fundamentos, objetivos, funcionalidades e práticas que justificam sua inserção no currículo da Educação Básica. São muitos questionamentos que devemos apontar e tentar esclarecer à luz de muitos e intensos debates sobre as práticas de ensino relacionadas à História. Práticas de suma importância, pois nos ajudam a refletir sobre nosso trabalho e o que devemos fazer a cada novo desafio que o próprio tempo nos apresenta e representam mudanças que nos obrigam, mesmo sem querermos, a nos aperfeiçoarmos a cada dia, a cada momento.

O ensino de História nos possibilita mostrar as diversas temporalidades, permitindo-nos várias interpretações de nossa história e suas relações com o presente, resultando em uma análise do que fomos e do que somos, pois sem essa simbiose entre o presente e o passado não poderemos relativizar nossas reflexões acerca de vários questionamentos históricos e atuais.

Um dos objetivos de se estudar História é dar sentido às experiências passadas e nos orientar a partir dessas experiências. O ensino de História deve contribuir para que nossos alunos problematizem essas experiências com a sua vida prática, pois, sem essa relação, perde-se o sentido de se estudar a História (RÜSEN, 2010). Devemos mostrar aos nossos alunos, por meio de nossas práticas pedagógicas, vários questionamentos acerca do ensinoaprendizagem em História, pois sem esses questionamentos perde-se a importância de tal estudo. O que caracteriza o ensino de História? Qual sua importância? Qual o sentido de se estudar a História? Quais as funções práticas que podemos exemplificar junto ao cotidiano dos nossos alunos? Como a didática da história de Rusen pode contribuir para o aprendizado em História? São perguntas fundamentais, que devem ser apresentadas aos nossos alunos, pois se não mostrarmos a importância de se estudar História, perder-se-á o sentido dessa aprendizagem. São essas perguntas as quais apontaremos algumas considerações, à guisa de resposta, e que ressaltam o significado desse trabalho envolvendo a concepção de didática da história do pensador alemão Jörn Rüsen e o que este pensador pode contribuir para o trabalho do professor na disciplina História no ensino fundamental e médio.

Para entendermos o sentido e a importância do ensino de História, primeiro temos de partir da sua significação e sua especificidade enquanto ciência, para, daí chegaremos ao 
ensino de História. O que diferencia a História de outras ciências? Do que a História trata realmente? O que é mais singular na História? Essas perguntas para historiadores podem parecer corriqueiras, mas é de extrema importância respondê-las e entendê-las junto ao ensino básico, pois fazem com que os alunos internalizem o sentido de estudar História e a sua relevância em suas vidas.

\section{A história como ciência}

A História se diferencia por uma questão singular, que torna seu caráter estritamente científico, e, a palavra que mais se adequa com a História e sua especificidade é o tempo, pois sem o tempo, o trabalho dos historiadores não existiria. O mesmo é essencial para historiadores e para aqueles que se interessam pelas experiências passadas (BARROS, 2013). Esse tempo regulamentado pelos historiadores é o marcado pelas suas pesquisas, que envolve o acontecimento, o evento e vários personagens dentro da narrativa, além da mais importante: a problematização. Sem uma problemática que envolva algum questionamento, dúvida ou até mesmo uma pergunta, a história se tornaria somente uma narrativa descritiva, sem sentido e sem nenhuma significação prática para as pessoas (RÜSEN, 2010). Sem essa utilização prática em nosso dia a dia ou em algum questionamento ou dúvida que nós tenhamos no presente, torna-se a história sem utilidade.

O tempo histórico é um tempo genuinamente humano e coletivo, diferenciando-se do tempo da natureza, regido por suas dinâmicas próprias. O mesmo é pensado dentro das experiências humanas, em suas mudanças, transformações e permanências que acontecem ao longo do tempo (BARROS, 2013). Estas percepções tornam o historiador um profissional que estuda essas experiências humanas ao longo do tempo e que as tornam acessível a um grande número de outros historiadores, especialistas ou leigos interessados nas narrativas reveladas pelos historiadores. Em síntese, o que existe é o tempo que os historiadores formulam, definem e concretizam em suas práticas de pesquisa, descritas pelas narrativas. Os conteúdos nos livros de História, da Educação Infantil, do Ensino Fundamental, do Ensino Médio e do Ensino Superior são pesquisas feitas por historiadores, ou por vezes outros, que revelam suas percepções, pontos de vista sobre vários assuntos, temas, conceitos, mas o que mais se identifica nesses conteúdos é a noção de tempo e a forma como o historiador o trabalha.

Os historiadores concebem o tempo de uma forma que facilite didaticamente as informações de uma determina época ou período. Esta datação e tempo dos historiadores não são exatos (no que se refere às passagens de uma fase para a outra), mas nos permitem situar 
acontecimentos importantes em nossa história e que, de alguma forma, nos trazem significações. $\mathrm{O}$ "[...] tempo dos historiadores, deste modo, ordena (define origens para os processos que examina, atribui-lhes sentido). Nesta operação, é já também um tempo territorializado" (BARROS, 2013, p. 27). O tempo territorializado é o tempo marcado pelos historiadores, dando sentido a determinadas marcações históricas referentes a acontecimentos, fatos ou épocas. Por exemplo: a Idade Antiga, a Idade Média, Brasil Colonial são marcações construídas pelos historiadores a fim de esclarecer alguns acontecimentos à luz de um período e de uma época determinada por eles.

O tempo histórico feito por historiadores se concretiza com a narrativa, que é a escrita por meio de sua pesquisa problematizada, através dos seus argumentos e de suas conclusões. Metodicamente os historiadores fazem a sua pesquisa histórica com base em argumentos sobre o tempo histórico por eles delimitado e o fazem dentro de critérios definidos cientificamente. Os historiadores dão sentido àquilo que, aos nossos olhos, não damos a devida importância, nos permitindo um olhar mais crítico sobre uma determinada época e lugar, trazendo à tona questionamentos que precisam ser elucidados ou ao menos debatido. Não que esses questionamentos sejam efetivamente respondidos ao se olhar o passado, mas nos ajudam a encontrar e relacionar fatos que estão ocorrendo no presente e que, de alguma forma, tem uma relação com o passado, podendo esclarecer muitos pontos. Muitas são as dúvidas e questionamentos que estão no presente e que, de alguma maneira, sempre buscamos respondê-los em relação ao passado.

As percepções do tempo são múltiplas e variadas, muitos estudiosos, filósofos, historiadores e demais especialistas discutem sobre essa temática, muitos divergem sobre suas interpretações e entendimento. As diversas sociedades e culturas também possuem diferentes formas de interpretação do tempo, que partem da vivência e de sua experiência coletiva. As percepções sobre o tempo nos direcionam para a questão da temporalidade. A “[...] temporalidade, portanto, é uma ideia que apenas adquire sentido através da percepção humana, da imaginação e das vivências do ser humano [...]" (BARROS, 2013 p. 32). A temporalidade é exclusivamente humana, nada tem a ver com o tempo físico da natureza, pois ela condiciona o ser humano em toda a sua totalidade. O tempo é bastante variado, como é, também, nossa vivência individual (tempo interno, subjetivo), pois cada um de nós tem diferentes maneiras de lidar com o tempo no nosso dia a dia, na nossa convivência com familiares, amigos e companheiros de trabalho. Temos o tempo coletivo, do calendário, do relógio, pois estes regulam as nossas vidas e ajudam a organizar nossas atividades cotidianas. 
Outro importante componente do tempo histórico diz respeito à duração, que é determinada a partir do entendimento dos historiadores sobre algum período, seu tempo e como o mesmo se processou. O tempo pode ser medido em detrimento das mudanças e transformações que ocorreram em uma determinada época e lugar. Assim,

[...] deve-se ressaltar que a "duração" refere-se ao ritmo, ao modo e à velocidade como se dá uma transformação ao longo do tempo, a durabilidade ou a permanência de algo até que seja substituído por algo novo ou por um novo estado. O conceito de "duração" - e as concomitantes sensações de variação na velocidade do tempo, independente da passagem do tempo cronológico (o tempo do relógio e do calendário) - remete de certo modo ao que classificaremos mais adiante como um "tempo interno" (um tempo que é sentido ou percebido subjetivamente pelo ser humano, e não um tempo cronométrico)”. (BARROS, 2013, p. 34).

As variações na velocidade do tempo são sentidas e tornam-se perceptíveis sob o olhar dos homens, que as identificam de acordo com as mudanças que sofreram ao longo do tempo, medindo a duração e tornando-as perceptíveis a vários aspectos da nossa vida social. As percepções sobre o tempo medidas pela duração dependem não somente das transformações, mas também da permanência. Os historiadores percebem essa dinâmica que ocorre em um determinado período ou época. $\mathrm{Na}$ verdade, os historiadores temporalizam a partir de algum acontecimento ou fato de acordo como ocorreu no passado, que marca e mede a duração sobre determinados fenômenos "observados".

Além das temporalidades e da duração, temos outro aspecto fundamental, que é o processo histórico. Entender a história como um processo é perceber que há como operar cognitivamente os fatos históricos a partir dos estudos dos historiadores, o que nos permitem entender o que aconteceu em determinada época com as suas transformações, mudanças e as permanências ocorridas. Desse modo, “[...] o processo histórico resulta da captação cognitiva dessas práticas, ordenadas e estruturadas de maneira racional pelos historiadores" (BRASIL, 2006, p. 73). A operacionalização obtida pelos historiadores é baseada em evidências, registros, documentos, por testemunhas etc, deixados pelas sociedades. Todo e qualquer grupo humano deixa marcas que o identificam e que preservam suas evidências.

\section{Rüsen e a didática da história}

Iremos expor agora, dentro de uma perspectiva da teoria e didática da História alemã, um pouco da teoria da consciência histórica de Jörn Rüsen e o que ele pode representar no aprendizado histórico de nossos alunos no Ensino Básico e na forma com que os professores de História podem ensinar História de maneira mais significativa. 
A didática e o ensino de História ganharam uma nova configuração com o filósofo alemão Jörn Rüsen. O mesmo enfatiza que aprender História tem um significado e como também o tem todo o entendimento da disciplina História como ciência. Aprender História é entender a sua importância, o sentido e a funcionalidade que a mesma apresenta e que vai muito mais além de seus princípios racionais e científicos. É uma construção de sentido através da experiência do tempo. O "[...] aprendizado histórico pode, portanto, ser compreendido como um processo mental de construção de sentido sobre a experiência no tempo através da narrativa histórica, na qual as competências surgem e se desenvolvem" (RÜSEN, 2014).

A significação da História traz para os alunos um aprendizado efetivo, pois sem trazer o significado de tais conteúdos históricos, os objetivos do aprendizado histórico se perdem. A significação dos conteúdos históricos torna-se essencial para a efetivação de tal aprendizado, permitindo um entendimento maior da importância de se estudar História.

É através da memória que se preservam, em parte, essas experiências do tempo. No entanto, não se podem conservar todas as experiências do tempo, seria irracional pensar ou tentar praticar tal ato, sendo que as experiências do tempo são muitas, variadas, múltiplas e complexas, e nenhum ser humano conseguiria tal feito. $\mathrm{O}$ entendimento sobre a perspectiva do passado funciona através da memória por conta da consciência histórica, sem a memória não teríamos, de fato, uma consciência histórica, ou melhor, a própria história.

A memória da consciência histórica é determinada por seus historiadores e pela forma como a narrativa histórica será construída a partir de seus próprios pressupostos teóricos. Tem um público ao qual é dirigida e as intenções de tal estudo se voltam para uma problemática fundamentada pelos historiadores. O público a que se dirigem essas publicações é variado, desde historiadores, jornalistas, ao público em geral, ou àqueles que se interessarem pelos trabalhos dos historiadores. No nosso caso, os alunos da Educação Básica e professores de História.

A didática da História vem contribuir para que nossos alunos aprendam História de maneira que o conhecimento histórico lhes traga um aprendizado significativo para suas vidas. Esta significação traz a ideia do próprio sujeito e do que a história representa para o mesmo, sendo uma importante ferramenta de conscientização dos aspectos temporais e da relação entre o presente e o passado. Poderíamos dizer conscientização e reflexão sobre determinado tema ou conceito, que é questionado e problematizado no presente a partir do qual recorremos ao passado para tirar as devidas dúvidas. $\mathrm{O}$ " [...] sujeito desenvolve um sentido para a alteridade temporal e para os processos temporais, que o conduz do outro 
experimentado ao eu vivenciado, tornando esse eu muito mais consciente e conferindo-lhe uma dinâmica temporal interna muito mais elaborada" (RÜSEN, 2010, p. 113). A relação presente e passado é de extrema importância para a efetivação do aprendizado histórico.

O sujeito ao adquirir aprendizado histórico utiliza-se das experiências do passado e o problematiza, dependendo das circunstâncias que são apresentadas a ele. O desenvolvimento das competências do aprendizado histórico aumenta o nível de consciência histórica desses sujeitos, resultando no nível de criticidade dos mesmos. O próprio nível de carência de nossos alunos revela o nível de consciência histórica que os mesmos apresentam, sendo de fundamental importância saber como está esta carência por determinados assuntos históricos, não o conteúdo ou assunto em si, mas o que eles trazem de significados para a vida prática deles, já que

[...] o aprendizado histórico acarreta aumento da competência de orientação. Essa competência diz respeito á função prática das experiências históricas interpretadas e ao uso dos saberes históricos, ordenados por modelos abrangentes de interpretação, com o fito de organizar a vida prática, com sentido, em meio aos processos temporais, ao longo dos quais os homens e seu mundo modificam. A interpretação humana do mundo e de si possuem sempre elementos históricos específicos. Esses elementos referem-se aos aspectos diacrônicos internos e externos da vida prática, ao quadro de orientação de agir e à identidade dos sujeitos (RÜSEN, 2010, p. 116).

Para Rüsen (2010), existem três dimensões da aprendizagem histórica: experiência, interpretação e orientação. Essas três operações estão interligadas e não podem ser entendidas separadamente. As mesmas determinam o nível de consciência histórica de cada sujeito que se submente ao aprendizado histórico, revelando a sua competência de orientação. Ou seja, o que de fato o conteúdo de História trouxe de significativo para a vida do sujeito? Qual o sentido de se estudar a História sem uma utilidade prática? Ensinar e aprender História vai muito além da decoração de datas, nomes de personagens históricos, eventos e acontecimentos. É enfatizar e problematizar o conhecimento histórico tornando-o significativo para aqueles que desejam aprender e ensinar este conhecimento.

Com a apropriação da História como um dado objetivo, partindo da experiência do passado, a consciência torna-se subjetiva, devido ao próprio processo de conscientização do sujeito, que a adquiriu após as experiências do passado, assim, de "[...] um lado um dado objetivo da mudança temporal do homem e de seu mundo no passado e de outro, um sujeito determinado, uma autocompensação e uma orientação da vida no tempo" (RÜSEN, 2010, p. 106). De forma mais clara: o aluno ao aprender História, aprende partindo de dados objetivos, que nada mais é que o conhecimento histórico, aquele feito por historiadores e especialistas, 
acrescendo-os ao seu arcabouço histórico pessoal. Ele se apropria deste conhecimento e faz com que este tenha um sentido, uma praticidade que alimenta a sua consciência, remodelando esta de acordo com suas convicções e interesses. A História, segundo Rüsen, é um mero construto subjetivo da consciência histórica.

O interesse do pensamento histórico está fundado pela práxis e pela identidade. A práxis entendida como a função específica e exclusiva do saber histórico na vida humana, da experiência dos homens no tempo, e, identidade que é a orientação da vida humana, em que o sujeito determina a sua consciência histórica. A práxis entendida como experiência e a identidade como "eu”. A práxis (fora) com a identidade (dentro) determinará a consciência histórica de cada sujeito.

O conhecimento histórico é baseado inteiramente na experiência e na objetividade presente na própria ciência. Sendo este conhecimento feito por historiadores e especialistas os quais utilizamos para o aprendizado de nossos alunos. Os nossos alunos aprendem este conhecimento e desenvolvem competências cognitivas, a partir da didática estabelecida pelos professores de História. Rüsen evidencia essa relação de aprendizado como fundamental para a efetivação do aprendizado histórico. Esta relação se organiza da seguinte forma: a objetividade e a subjetividade. A objetividade fundada no conhecimento histórico, que é elaborada por historiadores e especialistas, pautadas na própria discussão epistemológica, e a subjetividade, que é do próprio sujeito, de acordo com a sua orientação. Essa relação compõe o ensino de História e a própria consciência dos sujeitos inseridos no aprendizado. A formação histórica é constituída por esta relação e determinada pelos sujeitos inseridos no aprendizado histórico.

É um conjunto de competências que compõe o aprendizado histórico e que os professores tem que saber para poderem utilizá-los em suas aulas. São essas competências que vão orientar a vida prática e ao mesmo tempo darão sentido a história. Para Rüsen o aprendizado histórico é

[...] um conjunto de competências para orientar historicamente a vida prática, que pode ser descrito como a "competência narrativa" da consciência histórica. Ela é a capacidade das pessoas de constituir sentido histórico, com qual organizam temporalmente o âmbito cultural da orientação de sua vida prática e da interpretação de seu mundo e de si mesmas. Essa competência de orientação temporal do presente, mediante a memória consciente, é o resultado de um processo de aprendizado. Formação baseia-se no aprendizado e é, simultaneamente, um modo do próprio aprendizado. (RÜSEN, 2010, p. 104) 
Essa constituição do aprendizado histórico vai se efetivar na consciência histórica dos sujeitos envolvidos e adquirida por este mesmo aprendizado. É um conjunto de competências devidamente formuladas. São organizados e planejados com relação à vida prática dos alunos. Sendo que a consciência histórica dos sujeitos sempre vai se referir a sua própria condição de grupo e de sua cultura, pois essa consciência não é exclusivamente individual, mas sim coletiva. Para Rüsen (2010), a "consciência histórica é a constituição de sentido sobre a experiência do tempo, no modo de uma maneira que vai além dos limites de sua própria vida prática. A capacidade de constituir sentido necessita ser aprendida, e é no próprio processo dessa constituição de sentido" (RÜSEN, 2010, p. 104).

Para o autor, a consciência histórica é inerente ao homem e é determinada pelo próprio homem em seu contexto social, cultural, possuindo diferentes níveis em que se percebem e em que se insere no pensamento humano.

[...] consciência histórica não é uma meta, mas uma das condições da existência do pensamento: não está restrita a um período da história, a regiões do planeta, a classes sociais ou a indivíduos mais ou menos preparados para a reflexão histórica ou social em geral (CERRI, 2001, p. 03).

O pensar histórico é uma condição humana em que o sujeito no presente se direciona ao futuro com alguma perspectiva, pois o mesmo consegue se situar no mundo e em seu grupo social. A dimensão temporal passado, presente e futuro relaciona-se com a orientação, o modo como os sujeitos vão direcionar a sua capacidade cognitiva da consciência histórica, com a sua forma de pensar e agir perante o passado. Portanto, sobre como a experiência vivida vai lhe trazer algum significado que possa ter relação com sua vida.

No processo de desenvolvimento da consciência, Rüsen esquematizou uma tipologia geral do pensamento histórico, representada por meio de quatro tipos de consciência histórica: Tradicional, Exemplar, Crítica e Genética. O sujeito histórico se baseia em uma dessas consciências, que se forma a partir de suas perspectivas, inserindo-a em um determinado contexto e valores morais a ser seguido. O próprio sujeito adquire o seu nível de consciência de acordo com suas convicções, desejos e interesses, conforme seus valores morais, pois

[...] cada uma das manifestações da consciência histórica é o que gera um sentido na vida prática do indivíduo que racionaliza a história, não a percebendo apenas, como uma disciplina que existe pelo simples fato de existir, mas assim sendo, a História, uma disciplina capaz de ter um sentido racional e prático na vida dos indivíduos (MARRERA; SOUZA, 2013, p. 05). 
Cada consciência histórica é desenvolvida no ser humano da forma como ele interpreta sua vida prática, pelo próprio entendimento com a experiência histórica em que se orienta e dispõe suas perspectivas. São formas de raciocínio que os sujeitos formulam e definem de acordo com sua vida prática, dentro de seu cotidiano, orientados pelas três dimensões da aprendizagem histórica, faladas anteriormente: experiência, interpretação e orientação.

A consciência histórica do tipo tradicional relaciona-se com os costumes, regras e normas adotadas pelas tradições que passam de geração para geração, em um processo de perpetuidade e continuação de seus aspectos morais e culturais. Ligadas essencialmente às religiões, a uma tradição familiar, ou uma instituição que carrega valores, condutas que atravessam longos anos e séculos, se perpetuam através de seus descendentes e aqueles que querem preservar as suas tradições. A “[...] consciência histórica se mantém tradicional à medida que essa mentalidade transmitida é multiplicada por seus receptores e avança sobre as novas gerações que com ela se identifiquem" (ALVES, 2011, p. 61). O indivíduo que constrói o mundo através da consciência histórica tradicional o faz com o discurso trazendo o passado pelo presente, já que "a consciência histórica funciona em parte para manter vivas essas tradições" (RÜSEN, 2011, p. 62).

No tipo exemplar os sujeitos se orientam com exemplos e lições do passado, nos ensinando que ação devemos tomar e o que podemos evitar fazer. O indivíduo explica o mundo através de exemplos do passado, daquilo que experimentou, explicando o presente pelo passado no qual a "[...] história ensina a partir dos inúmeros acontecimentos do passado que transmite regras gerais do agir" (RÜSEN, 2010, p. 61).

O terceiro tipo de consciência, a crítica, se baseia na rejeição crítica de modelos históricos existentes, da cultura histórica existente. Utiliza-se de argumentos para derrubar modelos históricos vigentes, que desmontam em narrativas históricas produzidas por instituições, grupos, nações. A

[...] constituição crítica de sentido é o meio de uma comunicação intercultural, na qual o discurso histórico se modifica radicalmente, quando novas representações substituem as antigas, ou mesmo quando uma linguagem simbólica do histórico, inteiramente nova, varre a precedente (RÜSEN, 2010, p. 55).

Nesse tipo de consciência histórica, as pessoas não reconhecem a legitimidade histórica vigente, se orientando a partir da construção de uma nova narrativa. Seu objetivo é reunir argumentos, provas que derrubem a narrativa predominante, estabelecida por aqueles que a legitimaram durante muito tempo, uma vez que 
[...] tradicionalismo e exemplaridades históricas são descontinuadas pela constituição crítica de sentido. Modelos de orientação, tradição são questionadas em sua plausibilidade, pois são tidas como irrelevantes para a sociedade contemporânea do elaborador da crítica. A história atual como fornecedora de fatos que refutam a orientação predominante rompendo, portanto, com representações que perduram no tempo (ALVES, 2011, p. 69).

Existem vários exemplos de contra-narrativas históricas que combatem antigas narrativas predominantes, dentre elas estão: liberalismo econômico como contraposição ao protecionismo mercantilista; descentralização bipartite do poder político em detrimento da centralidade absolutista monárquica; superação do poder clerical pelo poder laico e secular; as propostas iluministas exemplificaram-se contra narrativas críticas as tradições e modelos existentes no Antigo Regime, vigente na sociedade ocidental; Marx e Engels criticaram o modelo capitalista e propuseram uma nova narrativa que visava à construção de um novo sistema e mentalidade. Nietzsche rejeitou o modelo moral existente ao decretar a morte do Deus que representava essa tradição na sociedade ocidental; as concepções 'pós-modernistas' também podem ser constituídas como construção histórica de sentido, apesar da própria problemática do termo pós-moderno (ALVES, 2011). Os exemplos citados são construções históricas de sentido crítico que se configuram como uma nova narrativa que contraria a narrativa existente e que tenta desconstruí-la para compor novas ideias e novas atitudes acerca das narrativas precedentes.

O quarto e último tipo de consciência histórica, a genética, baseia-se na argumentação e na negação das formas dominantes de sentido, não desprezando totalmente os modelos anteriores, atualizando, pegando exemplos para o presente com perspectivas para o futuro. A consciência histórica genética “[...] responde à experiência dinamizada do tempo presente nos saberes históricos elaborados geneticamente. Ela corresponde à representação do tempo transversal a todos os acontecimentos, caracterizado pela perspectiva de mudança" (RÜSEN, 2010, p. 61).

$\mathrm{Na}$ dimensão temporal do pensamento genético, o passado é resgatado pelo presente a partir de intenções para o futuro. $\mathrm{O}$ sujeito raciocina historicamente a partir das experiências vividas do passado pelo presente com vistas ao futuro. A perspectiva de mudança a partir de fatos concretos do passado (experiência) é o "motor" para a consciência histórica genética. Assim,

[...] a concepção determinante, pela qual o passado dinamizado temporalmente é articulado com a prática concreta do presente, de modo que o futuro apareça como 
chance de superação, é a da mudança constante, qualitativamente resistente (RÜSEN, 2010, p. 61).

Os quatro tipos de consciência histórica são formas de raciocínio histórico, constituídas a partir do sentido que as experiências passadas têm para um sujeito, grupo ou instituição. Essas experiências devem servir para orientar na vida cotidiana para uma perspectiva futura. Por exemplo, a consciência histórica tradicional e exemplar são formas pré-modernas do pensamento histórico, a crítica e a genética são formas modernas do pensamento histórico (ALVES, 2011). A consciência histórica genética é a forma mais desenvolvida de consciências. A crítica é a forma que serve como catalizadora da transformação. A tradicional e a exemplar são as formas mais rudimentar de consciência histórica, reverso da ciência histórica.

O estudo de Rüsen sobre a consciência histórica torna-se fundamental para entender os níveis de consciência histórica de nossos alunos e de como eles estão interpretando, orientando-os em sua vida prática e cotidiana. Importa conhecer, também, como a História está sendo ensinada e como nossos professores estão sendo preparados para ensinar História de uma forma que exige de nossos alunos criticidade e reflexão mais aprofundada sobre os conteúdos históricos. Temos de elevar o nível de consciência histórica de nossos alunos para que eles tenham um bom aprendizado, vejam e entendam a História como uma disciplina que desperte algum significado para suas vidas.

\section{Considerações finais}

Os vários termos utilizados na disciplina História, como tempo histórico, tempo dos historiadores, tempo humano e social, o tempo individual subjetivo, tempo coletivo, temporalidade, territorialidade, evento, acontecimento, duração, continuidade, permanência, mudanças e transformações, processo e estrutura, sistema, e demais, devem ser trabalhados por nós, professores, pois são de total importância para que nossos alunos entendam esses termos e o que eles significam. São termos constantes na História e que fazem parte do seu entendimento e de seus aspectos fundamentais. Devemos esclarecer esses termos para que possamos identificar certos aspectos históricos que estão presentes constantemente no conhecimento histórico, podendo, assim, efetivar o aprendizado histórico. Sem o entendimento e a definição desses termos na perspectiva histórica, poderemos falhar no processo de ensino-aprendizagem dos alunos, pois o ensino de História não pode ser baseado 
somente na exposição dos conteúdos, precisamos ter noção do que estamos ensinando aos nossos alunos.

Dentre os inúmeros termos descritos no parágrafo anterior, que estão presentes no conhecimento histórico, destacamos outros que também se fazem presentes, como cidadania, cultura, trabalho, poder e memória. Todos estes termos são fundamentais para o conhecimento histórico, estão bem explícitos nos PCNs (2006) e nos demais documentos do MEC, bem como na Lei $\mathrm{n}^{\circ} 10.639$, que obriga o ensino sobre História e Cultura Afro-Brasileira.

Existem, também, possíveis mudanças no currículo da disciplina de História, juntamente com demais disciplinas, ainda em discussão e que afetariam a História com futuras exclusões de conteúdos importantes para esta disciplina ${ }^{3}$. Como se trata de um processo ainda e curso, há duras críticas a essas novas mudanças no currículo de História e nas demais disciplinas, principalmente para as Ciências Humanas, a mais prejudicada. Há também uma forte presença da bancada evangélica propondo mudanças no currículo escolar e também na prática dos professores. Questões como "ideologia de gênero" e a "escola livre"4 tem sido propostas para a discussão de gênero nas escolas e, o segundo, refere-se à neutralidade do professor diante de seu ponto de vista e seu posicionamento perante algumas questões e ideias.

Queremos deixar claro que o currículo de História ou de quaisquer outras disciplinas não é e não poder ser estático, sempre há demanda por mudanças. Essas mudanças afetam diretamente os professores, alunos, ou melhor, a sociedade em geral, e podem permitir progressos ou retrocessos. De acordo com Rüsen, a consciência histórica fundamenta a ciência da História, de forma que a consciência humana se relaciona intimamente com a vida humana prática. Assim, a consciência histórica representa a capacidade dos homens de interpretarem suas experiências da evolução temporal, de seu mundo e de si mesmos, de tal forma que possam orientar sua vida prática no tempo, agindo intencionalmente.

A disciplina de História, ao ser trabalhada na educação básica, especialmente a didática da história de Rüsen, traz novos entendimentos sobre o processo de ensino e a aprendizagem. Ensinar História é antes de tudo, disponibilizar e ampliar possibilidades de

\footnotetext{
${ }^{3}$ Disponível em <http://g1.globo.com/educacao/noticia/2016/01/polemicas-do-novo-curriculo-de-historiaserao-temas-de-seminarios.html $>$. Disponível em $<$ http://basenacionalcomum.mec.gov.br/\#/site/inicio $>$. Acesso em 30 de junho de 2016.

${ }^{4}$ Disponível em: <http://g1.globo.com/pi/piaui/noticia/2016/03/projeto-que-proibe-debate-de-genero-na-escolagera-polemica-em-teresina.html> e disponível em

$<$ http://g1.globo.com/al/alagoas/noticia/2016/04/entenda-o-que-o-projeto-escola-livre-muda-no-ensinoestadual-em-alagoas.html . Acesso em 30 de junho de 2016.
} 
significados a partir dos quais os alunos possam construir identidade, representações e consciência do que a História pode nos revelar a partir da vivência e lugar social ocupado.

\section{REFERÊNCIAS}

ALVES, Ronaldo Cardoso. Aprender História com sentido para a vida: consciência histórica em estudantes brasileiros e portugueses. 2011. $322 \mathrm{f}$. Tese (Doutorado em Educação) - Faculdade de Educação, Universidade de São Paulo (FEUSP), São Paulo, 2011.

BARROS, José D’ Assunção. O tempo dos historiadores. Petrópolis, RJ: Vozes, 2013.

BRASIL. Lei $\mathbf{n}^{\mathbf{0}} \mathbf{. 1 0 . 6 3 9}$, de 9 de janeiro de 2003. Altera a Lei $\mathrm{n}^{\circ} .9 .394$, de 20 de dezembro de 1996, que estabelece as diretrizes e bases da educação nacional, para incluir no currículo oficial da Rede de Ensino a obrigatoriedade da temática "História e Cultura Afro-Brasileira", e dá outras providências. 2003. Disponível em <

http://www.planalto.gov.br/ccivil_03/leis/2003/L10.639.htm >. Acesso: 30. jul. 2016.

BRASIL. Secretaria de Educação Fundamental. Parâmetros Curriculares Nacionais: introdução aos parâmetros curriculares nacionais. Brasília: MEC/SEF, 1997. Disponível em < http://portal.mec.gov.br/seb/arquivos/pdf/livro01.pdf > . Acesso: 01 Out. 2017.

LEITE, Lucas; CÓLEN, Roberta. Entenda o que o Projeto Escola Livre muda no ensino estadual em Alagoas. G1 ALAGOAS - TV GAZETA, 28/04/2016. Disponível em < http://g1.globo.com/al/alagoas/noticia/2016/04/entenda-o-que-o-projeto-escola-livre-mudano-ensino-estadual-em-alagoas.html >. Acesso: 30 jun. 2016.

POLÊMICAS do novo currículo de história serão temas de seminários. G1 - EDUCAÇÃO, São Paulo, 05/01/2016. Disponível em < http:/g1.globo.com/educacao/noticia/2016/01/polemicas-do-novo-curriculo-de-historia-seraotemas-de-seminarios.html >. Disponível em $<$ http://basenacionalcomum.mec.gov.br/\#/site/inicio>. Acesso: 30 jun. 2016.

PROJETO que proíbe debate de gênero na escola gera polêmica em Teresina. G1 PIAUÍ TV Clube, 30/03/2016.Disponível em: < http://g1.globo.com/pi/piaui/noticia/2016/03/projetoque-proibe-debate-de-genero-na-escola-gera-polemica-em-teresina.html >. Acesso: 30 jun. 2016.

RÜSEN, Jörn. Cultura faz sentido: orientações entre o ontem e o amanhã. In: RÜSEN, Jörn. Potencialidades da formação de sentido. Tradução: Nélio Schneider. Petrópolis, RJ: Vozes, 2014. p. 251-299.

RÜSEN, Jörn. História viva: teoria da história: formas e funções do conhecimento histórico. Tradução: Estevão de Rezende Martins. 1.reimpr. Brasília: Editora da Universidade de Brasília, 2010.

RÜSEN, Jörn. O ensino de História. In: SHMIDT, Maria Auxiliadora; BARCA, Isabel; MARTINS, Estevão Rezende de. Experiência, orientação: as três dimensões da aprendizagem histórica e narrativa histórica - fundamentos, tipos, razão. Curitiba: Ed. UFPR, 2011. p.79-92. 
Recebido em 15/11/2017 Aceito em 05/01/2018 